\title{
Implementation of Game-based Learning in Higher Education: an example in HR Management
}

\author{
Marta Mas-Machuca, Alicia Jordan, Cristina Tresserres
}

Faculty Business Administration, Universitat Internacional de Catalunya, Spain.

\begin{abstract}
The benefits of game-based learning (GBL) are well justified in literature, but there are no abundant studies to its applications in different disciplines in Higher Education (HE). This method proposes a problem scenario within a play framework adding the elements of competition and chance. The main aim of this research is to describe and analyse the successful implementation of an application of a game-based learning in the subject of Human Resource Management (HRM) during the academic year 2018/2019. Students have had to face the resolution of a challenge in the field of HR proposed by a social enterprise. The activity, proposed as a competition, details also the student's perception by focus groups and surveys. The feedback collected shows that students positively assessed the new methodology and practical approach. The possibility of dealing with real organization's problems increments the student's motivation to learn. They consider that they have been able to acquire the core content of the selected topic by applying it in real situations. The empirical findings support the efficacy of game playing in $\mathrm{HE}$ and also shows that students enjoyed with this type of learning.
\end{abstract}

Keywords: Game-based learning; challenge; competition, HR Management; Higher Education. 


\section{Introduction}

As Tham and Tham (2012) mentioned on their pilot study on Game-Based Learning (GBL) in Singapore, it has been proven that students born in the digital world are neurologically different to those students from previous generations. Due to the easiness of accessing internet and the global digital environment, students in the $21^{\text {st }}$ century are provided with immediate information and feedback, and are always rewarded instantly for their efforts. This causes students to lose interest in traditional educational methods and prefere a more active and motivating methodology, rather than passively listening in class (Kenwright, 2016).

During the past years there has been an increasing concern about the students engagement in courses in Higher Education (HE), and awareness in the lack of students' motivation, achievements, attendance and participation has become a clear priority for educators (Nadolny \& Halabi, 2016; Tham \& Tham, 2012). Alternative teaching methods have been recently addressed by different authors with the objective of re-engaging students in $\mathrm{HE}$ (Ebner \& Holzinger, 2007; Nadolny \& Halabi, 2016).

Different studies have shown that learning with games provides a high variety of benefits (Tham \& Tham, 2012). Using a GBL methodology has proven that students maintain a higher level of participation and enjoy this kind of learning; as well as increasing their attention span, improving collaboration and social interactions and encouraging a healthy competition (Ebner \& Holzinger, 2007; Kenwright, 2016; Schmitz, Felicia, \& Bignami, 2015)

Over the past two decades, there has been a high increase on lecturers' interest between games and education (Hwang \& Wu, 2012; Kenwright, 2016). However, little evidence has been found of their application in HE or post-secondary level (Ebner \& Holzinger, 2007; Wiggins, 2016).

The main aim of this research is to describe and analyse the successful implementation of an application of a GBL method in HE. This research explains the experience of a class activity in which students learn in a practical way how to define the work competences. Students have to define the general competences of a social enterprise and their assignment to each job description. This activity is part of the Teaching Innovation project awarded by the Fundacion Puig (B-SMART) where students are expected to work in the classroom on real business challenges. The experience reported took place at the Universitat Internacional de Catalunya during the academic year 2018/2019. Students participating in this project were enrolled in the Human Resource Management course, a compulsory subject included in the third year of the Degree in Business Administration. 


\section{Theorethical foundations}

Although there are many definitions for GBL, a general and simple definition is the one provided by Wiggins (2016) in his study on the use of games, simulations, and gamification in HE. This study defines GBL as a type of learning in which actual games are used in the classroom to enhance learning and teaching.

When defining GBL, Ebner and Holzinger (2007) compared this methodology with problem-based learning. He stated that games include many characteristics of problem solving, i.e. an unknown outcome, multiple paths to a goal, construction of a problem context, collaboration in the case of multiple players etc., and they add the elements of competition and chance. On the other hand, Tham and Tham (2012), who analyzed the effectiveness of GBL as an instructional strategy for engaging and motivating students in HE in Singapore, adopted the following definition provided by Carson Learning Services (2006): Game-based learning is the process of taking an idea and creating an activity to deliver that idea in a manner that is motivating, challenging and fun, and has a measurable learning objective as a foundation.

GBL can often be confused with gamification. Although several authors use both terms interchangeably (Wiggins, 2016), Kenwright (2016) states that GBL is about the game and its cognitive residue, while gamification is about encouragement and the new technologies that stimulate this. When designing game solutions for the learning environment, there are different aspects to be considered. Although not all authors mention the same characteristics, they all mention similar fiels. For example, Kenwright (2016) in his study on GBL in HE, mentions the four part structures from Allen: (1) Context, (2) Challenge, (3) Action, and (4) Feedback; Nadolny and Halabi (2016) states that there are five characteristics that affect students' response to GBL methods, these are: (1) Playfulness, (2) Comparative pedagogy, (3) Instrumentalist, (4) Grade Status and (5) Performance; and finally, Tham and Tham (2012) mention the six characterisitcs according to Prensky (2001), that lead to a strong engagement of students on games: (1) rules, (2) goals/objectives, (3) outcomes/feedback, (4) conflict/competition/challenge/opposition, (5) interaction and (6) representation/story.

Although most authors differ on the exact definition for GBL, most authors agree on the fact that these games provide students with the possibility of solving real-life challenges and compromises within a safe environment and avoiding the fear of the real-world consequences (Ebner \& Holzinger, 2007; Kenwright, 2016; Nadolny \& Halabi, 2016). The main benefit of GBL has been identified as the students' engagement and motivation in the course (Ebner \& Holzinger, 2007; Kenwright, 2016; Nadolny \& Halabi, 2016; Wiggins, 2016). Nevertheless, different benefits have been observed in many studies: class attendance and participation (Nadolny \& Halabi, 2016), creativity (Nadolny \& Halabi, 
2016), collaboration and social interactions (Schmitz et al., 2015) and others such as attention spam, mental flexibility, productivity, and healthy competition (Kenwright, 2016).

Finally, it is important to consider the dangers of this methodology. For instance, as Kenwright (2016) mentions in his study, when technology is used professors should consider the expertise their students have as it could become a barrier in the learning process. Also, GBL can be time-consuming both, when preparing the course and tracking the progress. GBL is only successful when solutions are well designed; limitations and challenges arise when the game has not been thought thoroughly and curricular objectives are not achieved, so it is important to plan carefully in order to achieve the academic objectives (Kenwright, 2016).

\section{Description of the competition}

The real challenge was proposed by SaóPrat. It is a non-profit, socio-educational entity, declared of public utility, which was born in 2004 in El Prat de Llobregat. The students had to prepare a report with the following information: (i) Catalogue of competencies according to the needs of the entity SAOPRAT. Build a list of competences (reduce to 15 transversal competences); (ii) definition of each competence; (iii) for each job, they must propose 4-5 transversal skills.

The 55 students enrolled in the subject were group in groups of 5/6 proposed by the lecturers (based on previous team-works). Creativity, justification of the choice of competencies and detail of the methodology followed were valued. During the group work, it was recommended to apply some element of design thinking methodology. Lecturers provided students the required material (Drive Folder with all the documents of the job description, organizational chart, etc), post-it, DIN 3 papers, etc.

One main session (2 hours) was carried out by the lecturers and the responsables of SaóPrat with the students. After this session, the students had to work in teams outside the classroom with the on-line support of the lecturers (on average a total of 16 hours per team). Approximately, $20 \%$ of the work was done during class hours, while the rest was performed after classes.

The grading of the work had a higher weighting than other work carried out during the course within the continuous evaluation grade. The work was be evaluated by the HR lecturers and the 3 best opted to make a final presentation in the social enterprise. The grades of the presentations were decided through a discussion among the two lecturers of the subject, who proceeded with the selection of the three best proposals (taking into account different criteria: structure, content and format). The oral presentation in the organization was assessed by the lecturesrs and the manager of SaóPrat. The mark of the 
whole exercise (work + presentation) is considered the mark of the final exam of the subject, leaving these students free to take the final exam. International students who take the course first must take the exam in all cases. Lecturers consider that this assessment is motivating for students to work hard and achieve excellence results.

The lecturer's dedication changes when it comes to preparing this type of methodology. In the first place, the lecturer must know in depth the needs of the company and the problems to be solved in order to adapt them to the contents, level and demands that can be asked of the students. On the other hand, the role of the teacher changes. Instead of having an active position in the teaching process, he or she takes on the role of facilitator in this process. Finally, the teacher must reflect on the mechanisms for evaluating learning and the incentives (prizes) that must be established for the activity to be inspiring and attractive to students. Competition should be approached as something positive, in order to raise the score and not to penalize (Burguillo, 2010). In conclusion, this type of methodology affects the teacher's usual way (competition vs. traditional class).

\section{Results and Discussion}

During the day of the final exam and the final presentations, all students were given a survey to answer. The survey was made up of 23 statements grouped in five dimensions that had to be answered using a Likert scale from 1 to 5; one meaning the student totally disagreed with the statement and 5 meaning the student totally agreed. The first group of questions involved aspects related to competition. The second dimension covered aspects related to teamwork and collaboration, the third one analyzed the evaluation and knowledge acquired and the fourth compared the GBL methodology with traditional teaching. Finally, the last dimension included general questions about the course .

From the 55 students enrolled in the course 33 answers were obtained (out of 38, 86\% of response rate) from those students that had to take the final exam and 16 answers (out of $17,94,11 \%$ of response rate) from those students that did the final presentation.

The survey shows that those students who arrived to the final stage of the competition and presented their projects to the social enterprise, were more satisfied than those students who had to take the final exam.

Regarding the first dimension (competition), it is shown that the finalist students consider themselves more competitive. However, in general, both groups of students confirmed that the fact that the presentations were involved in a competition made them take it more seriously than if it had been a simple class presentation (mean of 3.67).

All students stated that this project has helped them improve the relationship between team members. Still, the three teams arriving to the final competition gave a higher mark to this 
statement (3.36 vs. 4.16). This may be due to the fact that students not doing the final exam had to prepare the final presentation to be exposed at the social enterprise, having to work more hours together. This fact, together with the excellent quality of the work presented could also justify why students arriving to the final presentation tend to say that all team members worked equally (3.06 vs. 4.19).

When analyzing the evaluation dimension, in general, all students consider that the time dedicated to prepare this competition has been adequate to the weight it has in the course. Students taking the final exam think that they finish with more knowledge than those not taking it; this would explain why they think it is unfair for the winning students not to take the final test. However, these results could be biased by the students' perception of memorizing concepts for an exam. The final exam evaluated the topic in a very theoretical way, so the theoretical definitions were memorized much better by those students taking the test. However, it is important to notice that the practical knowledge and real-life experience were acquired by every student as they all confirmed to be engaged and motivated to win the competition by developing this practical case.

Comparing this teaching methodology to traditional learning all students confirmed that this activity was more time-consuming than a traditional lecture would have been (average of 3.90). However all students considered this activity much more dynamic than traditional learning (4.10) and that it made them feel more motivated to learn (3.67).

Finally, regarding the general aspects of the course, most students confirmed that this competition gave them a better understanding on the concepts of the course (3.71) as well as of the real problems of an enterprise (3.98) and how a company works (3.71). All students considered the activity useful (3.89) and were satisfied on how the activity took place (3.78).

Different focus groups were done with students to analyze in depth the results obtained on the surveys. In general, all the interviews confirmed the results previously explained.

All students said that the fact of the project being a competition between teams and not having to take the final exam, was an extra motivation for them to work harder and increase their interest and productivity.

Another interesting point mentioned by different students (both, those who had to take the final test and those who did not) found the instructions of the project and the initial material a little confusing. According to most of the students, there was too much material facilitated by the social enterprise and lots of time was needed to analyze and organize all the material.

Considering that professors of the course assigned each team member to a specific team, students had different opinions regarding this matter. Some students said that not all members worked equally and that they would rather choose their own team to avoid this 
situation. However, other students mentioned that this gave them the opportunity to meet new people and as it was a team evaluation, all team members worked together to achieve the same goal (presenting their project to the social enterprise and not having to take the final exam).

Since the company involved in the projects had a social aim, some students felt more encouraged to excel on their work as they new they were helping a company with fewer resources.

Finally, one of the the points that was most brought up by students was the fact of having a real life experience. Dealing with real company problems helped students understand better how a real HR department works. Students stated that although it was more timeconsuming than a traditional course, they enjoyed it more and found it dynamic and interactive.

When they were asked about how to improve the course, students suggested that more work could have been done during course hours instead of after class and that a presentation could have been done halfway through the course to make sure teams were moving in the right direction.

\section{Conclusions}

The main aim of this research was to analyze the implementation of GBL in the subject of Human Resource Management (HRM) during the academic year 2018/2019.

As mentioned earlier, surveys confirmed that this approach gave students a better understanding on the concepts of the course (average of 3.71 out of 5) as well as of the real problems of a company (3.98) and how a company really works (3.71). Finally, all students considered the activity useful (3.89) and were satisfied on how the activity took place (3.78).

The focus groups enphasyzed on the fact that the game was presented as a competition and according to students, this motivated them to work harder and enjoy the project. This confirms the findings of Tham and Tham (2012) on their study on the effectiveness of GBL as an instructional strategy for engaging and motivating students in HE in Singapore.

Regarding future research, the impact of the students' nationality could be analyzed. Students enrolled in this course were both, Spanish and international students (mainly italian). Findings show that Italian students, in general, found this project more innovative and entertaning than those from Spain. Also, out of the 17 finalist students, only three were Spanish, suggesting maybe that they this methodology has different effects depending on the different educational backgrounds. 


\section{Acknowledgements}

The authors would like to express their gratitude to all members in the B-SMART Project (Teaching Innovation project awarded by the Fundacion Puig) for their contribution and for facilitating and encouraging knowledge transfer between the university and businesses. We would also like to thank Sao Prat responsibles for their participation in this competition.

\section{References}

Carson Learning Services. (2006). Instructional design: Game-based Learning. San Francisco, CA.

Ebner, M., \& Holzinger, A. (2007). Successful implementation of user-centered game based learning in higher education: An example from civil engineering. Computers and Education, 49(3), 873-890. https://doi.org/10.1016/j.compedu.2005.11.026

Hwang, G. J., \& Wu, P. H. (2012). Advancements and trends in digital game-based learning research: A review of publications in selected journals from 2001 to 2010. British Journal of Educational Technology, 43(1), 6-10. https://doi.org/10.1111/j.14678535.2011.01242.x

Kenwright, B. (2016). Game-Based Learning in Higher Education.

Nadolny, L., \& Halabi, A. (2016). Student Participation and Achievement in a Large Lecture Course With Game-Based Learning. Simulation and Gaming, 47(1), 51-72. https://doi.org/10.1177/1046878115620388

Prensky, M. (2001). Digital Game-Based Learning. New York, NY: McGraw-Hill.

Schmitz, B., Felicia, P., \& Bignami, F. (2015). Acceptance and Use of Game-Based Learning in Vocational Education and Training. International Journal of Game-Based Learning, 5(4), 50-63. https://doi.org/10.4018/ijgbl.2015100104

Tham, L., \& Tham, R. (2012). Is game-based learning an effective instructional strategy to engage students in higher education in Singapore? A pilot study. The Journal for the Research Center for Educational Technology, 8(1), 2-10. Retrieved from http://www.rcetj.org/index.php/rcetj/article/view/160/261

Wiggins, B. E. (2016). An Overview and Study on the Use of Games, Simulations, and Gamification in Higher Education. International Journal of Game-Based Learning, 6(1), 18-29. https://doi.org/10.4018/ijgbl.2016010102 